\title{
Rothenburg
}

Aktienoptionen in der Verschmelzung 
Rechtsfragen der

Band 124

Handelsgesellschaften 


\section{Aktienoptionen in der Verschmelzung}

von

Dr. Vera Rothenburg

2009

Verlag

Dr.OttoSchmidt

Köln 


\section{21}

Gedruckt mit Unterstititzung des Förderungs- und Beibilfefonds Wissenschaft der VG WORT

Bibliografische Information

der Deutschen Nationalbibliothek

Die Deutsche Nationalbibliothek verzeichnet diese

Publikation in der Deutschen Nationalbibliografie; detaillierte bibliografische Daten sind in Internet über http://nb.d-nb.de abrufbar.

Verlag Dr. Otto Schmidt KG

Gustay-Heinemann-Ufer 58,50968 Köln

Tel. 0221/93738-01, Fax 02 21/93738-943

info@otto-schmidt.de

www.otto-schmidt.de

ISBN 978-3-504-64676-9

@2009 by Verlag Dr. Otto Schmidt KG, Köln

Das Werk einschließlich aller seiner Teile ist urheberrechtlich geschützt. Jede Verwertung, die nicht ausdrücklich vom Urheberrechtsgesetz augelassen ist, bedarf der vorherigen Zustimmung des Verlages. Das gilt insbesondere fïr Vervielfaltigungen, Bearbeitungen, Ubersetzungen, Mikroverlilmungen und die Einspeicherung und Verarbeitung in elektronischen Systemen.

Das verwendete Papier ist aus chlorfrei gebleichten Rohstoffen hergestellt, holz- und säurefrei, alterungsbeståndig und unweltfreundlich.

Einbandgestaltung nach einem Entwurf vom: Jan P. Lichtenford Druck und Verarbeitung: Bercker, Kevelaer Printed in Gemany 